\title{
New developments in the anti-neoplastic drug management of ovarian cancer
}

\author{
Maurie Markman
}

Address: Cancer Treatment Centers of America, Eastern Regional Medical Center, 1331 East Wyoming Avenue, Philadelphia, PA 19124, USA

Email: maurie.markman@ctca-hope.com

Fl000Prime Reports 2013, 5:48 (doi:10.12703/P5-48)

This is an open-access article distributed under the terms of the Creative Commons Attribution-Non Commercial License (http://creativecommons.org/licenses/by-nc/3.0/legalcode), which permits unrestricted use, distribution, and reproduction in any medium, provided the original work is properly cited. You may not use this work for commercial purposes.

The electronic version of this article is the complete one and can be found at: http://fl000.com/prime/reports/m/5/48

\begin{abstract}
Over the past several years, there have been a number of relevant evidence-based randomized trials that have the potential to change the standard management paradigm in the malignancy of ovarian cancer and (most importantly) enhance clinically relevant outcomes. This commentary will briefly review these trials.
\end{abstract}

Bevacizumab in the treatment of ovarian cancer Four randomized trials have been reported in three specific clinical settings that clearly document both the biological and clinical impact of bevacizumab, a human recombinant monoclonal antibody directed against vascular endothelial growth factor (Table 1) [1-4]. However, while there has been a documented improvement in progression-free survival (PFS) in each of the studies, they have failed to reveal superior overall survival for patients managed on the bevacizumab-containing treatment arm.

While it is recognized that not all agree on the interpretation of these findings, it is the opinion of this commentator that it is highly likely the failure to convert a statistically significant improvement in PFS to superior overall survival is a direct result of the fact that the large majority of ovarian cancer patients receive multiple antineoplastic agents (including possibly bevacizumab) previously demonstrated to have both biological and clinical activity in ovarian cancer after they complete treatment on the study, which may favorably impact their ultimate survival [5].

Despite the solid evidence-based results of these multiple phase 3 randomized trials (and perhaps at least partly because of them), there remain many quite relevant unanswered questions regarding the optimal utilization of bevacizumab in the management of ovarian cancer
(Table 2). Hopefully, future clinical trials will help resolve the uncertainties surrounding the use of this important anti-neoplastic agent. The urgency in providing these answers is heightened when one recognizes the major financial impact associated with the routine administration of bevacizumab.

\section{Other anti-angiogenic agents in ovarian cancer} A preliminary report of the results of a phase 3 trial examining a potential role for pazopanib employed as a "maintenance" strategy following the completion of primary cytotoxic chemotherapy has revealed that the administration of this agent (compared to placebo) improves PFS (median 17.9 months versus 12.3 months; $P=0.0021$; hazard ratio [HR] 0.766) [6]. Although data on overall survival remain immature, the initial reported data do not suggest this strategy improves overall survival. Similar to the previously discussed situation with bevacizumab, this outcome is highly likely to be a result of the multiple anti-neoplastic agents delivered to patients once they have completed treatment on this trial [5]. Data from phase 3 trials examining several additional antiangiogenic drugs (nintedanib; cediranib; trebananib) in ovarian cancer management are eagerly awaited [7].

\section{Olaparib in the management of ovarian cancer}

Phase 2 trials have previously demonstrated the clinical activity of single-agent olaparib, a poly(ADP-ribose) 
Table I. Phase 3 randomized trials comparing cytotoxic chemotherapy with or without bevacizumab in epithelial ovarian cancer

\begin{tabular}{|c|c|}
\hline Study & Results \\
\hline $\begin{array}{l}\text { "GOG } 2 \text { I8" - Carboplatin/paclitaxel + BEV in primary treatment of advanced ovarian } \\
\text { cancer (3-arm, "placebo-controlled" - chemo alone; chemo + BEV [only during chemo]; } \\
\text { chemo + BEV [during chemo and "maintenance"]) }\end{array}$ & $\begin{array}{l}\text { Improved PFS (median I } 4.1 \text { versus } 10.3 \text { months; } P<0.00 \text { I) } \\
\text { for BEV (with chemo and "maintenance") compared to } \\
\text { chemo alone }\end{array}$ \\
\hline $\begin{array}{l}\text { "ICON 7" - Carboplatin/paclitaxel + BEV in primary treatment of advanced ovarian cancer } \\
\text { (2-arm, open-label - chemotherapy alone; chemo + BEV [during chemo and "maintenance"]) }\end{array}$ & $\begin{array}{l}\text { Improved PFS (median } 24.1 \text { versus } 22.4 \text { months; } P=0.04 \text { ) } \\
\text { for chemo + BEV compared to chemo alone }\end{array}$ \\
\hline $\begin{array}{l}\text { "OCEANS" - Carboplatin/gemcitabine + BEV in recurrent potentially platinum-sensitive } \\
\text { (minimum } 6 \text { months following completion of primary platinum-based chemotherapy) } \\
\text { ovarian cancer (placebo-controlled) }\end{array}$ & $\begin{array}{l}\text { Improved PFS (median I } 2.4 \text { versus } 8.4 \text { months; } P<0.000 \text { I) } \\
\text { for chemo + BEV compared to chemo alone }\end{array}$ \\
\hline $\begin{array}{l}\text { "AURELIA" - Pegylated liposomal doxorubicin, OR topotecan, OR weekly paclitaxel + } \\
\text { BEV in platinum-resistant (<6-month platinum-free interval) ovarian cancer }\end{array}$ & $\begin{array}{l}\text { Improved PFS (median } 6.7 \text { versus } 3.4 \text { months; } P<0.001 \text { ) for } \\
\text { chemo + BEV compared to chemo alone }\end{array}$ \\
\hline
\end{tabular}

BEV, bevacizumab; GOG, Gynecologic Oncology Group; ICON 7, International Collaborative Ovarian Neoplasm Group; OCEANS, Ovarian Cancer Study Comparing the Efficacy and Safety of Chemotherapy and Anti-Angiogenic Therapy in Platinum-Sensitive Recurrent Disease; PFS, progression-free survival.

Table 2. Unresolved issues in the delivery of bevacizumab in the management of ovarian cancer

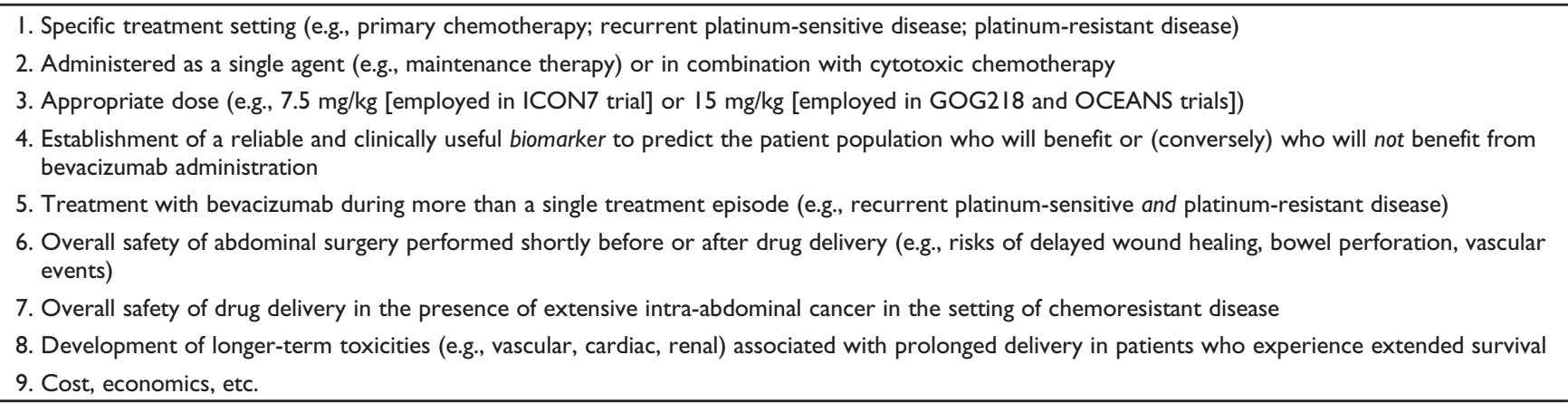

GOG, Gynecologic Oncology Group; ICON7, International Collaborative Ovarian Neoplasm Group; OCEANS, Ovarian Cancer Study Comparing the Efficacy and Safety of Chemotherapy and Anti-Angiogenic Therapy in Platinum-Sensitive Recurrent Disease.

polymerase (PARP) inhibitor, in ovarian cancer patients with a germline BRCA 1 or BRCA 2 mutation [8]. As preclinical data revealed similarities in the molecular profiles of BRCA mutation-positive ovarian cancers and nonmutant-positive high-grade serous ovarian tumors, investigators conducted a phase 2 randomized trial $(n=265$ patients) comparing olaparib to "placebo" employed as a single-agent "maintenance" strategy in women with highgrade serious ovarian cancers who had achieved a response or exhibited stable disease following a secondline platinum-based chemotherapy regimen [9]. The study revealed a highly statistically significant improvement in PFS (median 8.4 months versus 4.8 months; $P<0.001$; HR 0.35) in favor of the olaparib strategy. Again, there was no difference in overall survival between the study groups [5].

In a preliminary report of a re-evaluation of this study population, the investigators were able to examine 218 (of the original 265) patients for the presence of germline BRCA mutations [10]. This analysis revealed an even greater impact of olaparib (compared to placebo) on PFS (median 11.2 months versus 4.1 months; $P<0.001$; HR 0.17) in patients with a germline BRCA mutation. It was also noted that of the 37 patients with a known germline BRCA mutation who were treated with "placebo" in this trial, 13 subsequently received a PARP inhibitor (in addition to other biologically active agents this group of patients may have also received following completion of the trial), potentially seriously compromising an analysis of an overall survival endpoint in this study [5].

\section{Cytotoxic anti-neoplastic agents}

Despite the enthusiasm for the development of novel anti-neoplastic agents in ovarian cancer, it must be remembered that classical "cytotoxic" anti-neoplastic agents (e.g. the "platinums", the "taxanes") remain the cornerstone in disease management. Furthermore, clinical research designed to optimize the utilization of such 
agents remains active in the gynecologic oncology investigative community.

For example, a phase 3 randomized trial revealed the superiority (PFS endpoint) of a second-line regimen of carboplatin plus pegylated liposomal doxorubicin compared to carboplatin plus paclitaxel in recurrent, potentially platinum-sensitive, ovarian cancer [11], possibly due to a provocative, essentially unexplained, and striking reduction in carboplatin-associated hypersensitivity reactions when this agent is delivered with pegylated liposomal doxorubicin in the second-line setting $[11,12]$.

There has been a particular focus on strategies designed to optimize the method of paclitaxel administration in ovarian cancer. The Japanese Gynecologic Oncology Group reported the results of a phase 3 trial demonstrating the superiority (PFS and overall survival) associated with administering paclitaxel on a weekly ( $80 \mathrm{mg} / \mathrm{m}^{2}$ per week) schedule compared to the "standard" every-3-week regimen [13]. In this program, the carboplatin was delivered every 3 weeks.

In a preliminary report of a multi-institutional phase 3 randomized trial, investigators explored a quite different "weekly strategy" with both the paclitaxel $\left(60 \mathrm{mg} / \mathrm{m}^{2}\right.$ per week) and carboplatin (AUC 2/week) administered by this novel approach [14]. Compared to "standard" every-3week carboplatin plus paclitaxel, the weekly (paclitaxel and carboplatin) schedule was revealed to produce equivalent efficacy but with substantially reduced side effects. Whether the differences in efficacy and toxicity outcomes between these two studies relate to the weekly dose of paclitaxel delivered, the approaches to the administration of carboplatin, unique genetic or environmental backgrounds of the patient populations, or a combination of these factors remains unknown and worthy of future investigative efforts.

\section{Abbreviations}

HR, hazard ratio; PARP, poly(ADP-ribose) polymerase; PFS, progression-free survival.

\section{Disclosures}

I would list potential "conflicts of interest" to include participation in medical advisory boards for: Genentech, Glaxo-Smith Kline, Amgen, Boehringer-Ingelheim, Celgene, Novartis.

\section{References}

I. Burger RA, Brady MF, Bookman MA, Fleming GF, Monk BJ, Huang $H$, Mannel RS, Homesley HD, Fowler J, Greer BE, Boente M, Birrer MJ,
Liang SX: Incorporation of bevacizumab in the primary treatment of ovarian cancer. N Engl J Med 20I I, 365:2473-83.

\section{FIOOOPrime}

2. Perren TJ, Swart AM, Pfisterer J, Ledermann JA, Pujade-Lauraine E, Kristensen G, Carey MS, Beale P, Cervantes A, Kurzeder C, Du Bois A Sehouli J, Kimmig R, Stähle A, Collinson F, Essapen S, Gourley C, Lortholary A, Selle F, Mirza MR, Leminen A, Plante M, Stark D, Qian W, Parmar MKB, Oza AM: A phase 3 trial of bevacizumab in ovarian cancer. N Engl J Med 20II, 365:2484-96.

\section{FlOOOPrime}

\section{RECOMMENDED}

3. Aghajanian C, Blank SV, Goff BA, Judson PL, Teneriello MG, Husain A, Sovak MA, Yi J, Nycum LR: OCEANS: a randomized, doubleblind, placebo-controlled phase III trial of chemotherapy with or without bevacizumab in patients with platinum-sensitive recurrent epithelial ovarian, primary peritoneal, or fallopian tube cancer. J Clin Oncol 2012, 30:2039-45.

\section{FlOOOPrime}

RECOMMENDED

4. Pujade-Lauraine $E$, Hilpert $F$, Weber B, Reuss A, Poveda A, Kristensen G, Sorio R, Vergote IB, Witteveen P, Bamias A, Pereira D, Wimberger P, Oaknin A, Mirza MR, Follana P, Bollag DT, Ray-Coquard I and AURELIA Investigators: AURELIA: A randomized phase III trial evaluating bevacizumab plus chemotherapy for platinum-resistant ovarian cancer. J Clin Oncol 2012, 30(suppl; LBA 5002).

5. Broglio KR, Berry DA: Detecting an overall survival benefit that is derived from progression-free survival. J Natl Cancer Inst 2009, 101:1642-9.

6. Du Bois A, Floquet A, Kim JW, Rau J, Del Campo JM, Friedlander M, Pignata S, Fujiwara K, Vergote I, Colombo N, Mirza MR, Monk BJ, Wimberger P, Ray-Coquard I, Zang R, Diaz-Padilla I, Baumann KH, Kim JH, Harter $\mathrm{P}$ and on behalf of an Intergroup consortium. Randomized, double-blind, phase III trial of pazopanib versus placebo in women who have progressed after first-line chemotherapy for advanced epithelial ovarian, fallopian tube, or primary peritoneal cancer: Results of an international Intergroup trial (AGO-OVAR I6). J Clin Oncol 2013, 3 I (suppl; LBA 5503).

7. Burger RA: Overview of anti-angiogenic agents in development for ovarian cancer. Gynecol Oncol 20 I I, I 2 I:230-8.

8. Fong PC, Yap TA, Boss DS, Carden CP, Mergui-Roelvink M, Gourley C, de Greve J, Lubinski J, Shanley S, Messiou C, A'Hern R, Tutt A, Ashworth A, Stone J, Carmichael J, Schellens JHM, Bono JS de, Kaye SB: Poly(ADP)-ribose polymerase inhibition: frequent durable responses in BRCA carrier ovarian cancer correlating with platinum-free interval. J Clin Oncol 2010, 28:25I2-9.

\section{FlOOOPrime
RECOMMENDED}

9. Ledermann J, Harter P, Gourley C, Friedlander M, Vergote I, Rustin G, Scott C, Meier W, Shapira-Frommer R, Safra T, Matei D, Macpherson E, Watkins C, Carmichael J, Matulonis U: Olaparib maintenance therapy in platinum-sensitive relapsed ovarian cancer. N Engl J Med 2012, 366: I382-92.

\section{FlOOOPrime}

RECOMMENDED

10. Ledermann JA, Harter P, Gourley C, Friedlander M, Vergote I, Rustin GJS, Scott CL, Meier W, Shapira-Frommer R, Safra T, Matei D, Fielding A, Macpherson E, Dougherty B, Jürgensmeier JM, Orr M, Matulonis $U$ : Olaparib maintenance therapy in patients with platinum-sensitive relapsed serous ovarian cancer and a BRCA mutation. J Clin Oncol 2013, 3 I (suppl; Abstract 5505).

II. Pujade-Lauraine E, Wagner $U$, Aavall-Lundqvist E, Gebski V, Heywood M, Vasey PA, Volgger B, Vergote I, Pignata S, Ferrero A, Sehouli J, Lortholary A, Kristensen G, Jackisch C, Joly F, Brown C, Le Fur N, Du Bois A: Pegylated liposomal Doxorubicin and Carboplatin compared with Paclitaxel and Carboplatin for 
patients with platinum-sensitive ovarian cancer in late relapse. J Clin Oncol 2010, 28:3323-9.

\section{FlOOOPrime}

12. Markman M, Moon J, Wilczynski S, Lopez AM, Rowland KM, Michelin DP, Lanzotti VJ, Anderson GL, Alberts DS: Single agent carboplatin versus carboplatin plus pegylated liposomal doxorubicin in recurrent ovarian cancer: final survival results of a SWOG (S0200) phase 3 randomized trial. Gynecol Oncol 2010, I 1 6:323-5.

13. Katsumata N, Yasuda M, Takahashi F, Isonishi S, Jobo T, Aoki D, Tsuda H, Sugiyama T, Kodama S, Kimura E, Ochiai K, Noda K: Dosedense paclitaxel once a week in combination with carboplatin every 3 weeks for advanced ovarian cancer: a phase 3, openlabel, randomised controlled trial. Lancet 2009, 374:133|-8.

FlOOOPrime

14. Pignata S, Scambia G, Lauria R, Raspagliesi F, Panici PB, Cormio G, Katsaros D, Sorio R, Cavazzini G, Ferrandina G, Breda E, Murgia V Sacco C, Sierra NMA, Pisano C, Salutari V, Weber BE, PujadeLauraine $\mathrm{E}$, Gallo $\mathrm{C}$, Perrone F: A randomized multicenter phase III study comparing weekly versus every 3 weeks carboplatin plus paclitaxel in patients with advanced ovarian cancer: Multicenter Italian Trials in Ovarian Cancer (MITO-7)European Network of Gynaecological Oncological Trial Groups (ENGOT-ov-I0) and Gynecologic Cancer Intergroup (GCIG) trial. J Clin Oncol 20I3, 3 I (suppl; LBA550I) 